\title{
The evolution of sialendoscopy in clinical practice
}

SADJ October 2019, Vol. 74 No. 9 p485 - p490

N Kana ${ }^{1}$, S Maharaj ${ }^{2}$

\section{ABSTRACT}

Sialendoscopy is a relatively new technique first described by Katz et al. in 1991. ${ }^{1}$ The technique of sialendoscopy entails using semirigid endoscopes to cannulate and view the interior of salivary ducts and to manage obstructions within these ducts.

This technique provides a minimally invasive alternative to the traditional very invasive techniques of salivary gland excision. It can be used as a diagnostic instrument and as a therapeutic intervention for various causes of salivary duct obstruction.

The objective of this research report was to assess the outcomes of sialendoscopy, performed over a 10-year period from 2008 and 2018 in a private practice setting in South Africa.

The outcomes of sialendoscopy as a therapeutic intervention were compared for different aetiologies of salivary duct obstruction. A therapeutic sialendoscopy was deemed successful if after the obstruction was treated, the patient remained asymptomatic at follow up and if no complications ensued during sialendoscopy.

The success rate in this study was $73.3 \%$. The cases that were considered failures were due to excessive bleeding, abscess formation and failure of calculus retrieval. Despite our small sample size, it appears that sialendoscopy offers good outcomes for both the diagnosis and the treatment of the majority of cases of salivary ductal obstruction and that it is the gold standard for the first line management of this pathology.

\section{Keywords}

Sialendoscopy, sialadenectomy.

\section{Author affiliations:}

1. Nadir Kana: MBChB FCORL(SA)., Affiliate of The Department of Otorhinolaryngology, Wits University, In full time private practice at Milpark and Mulbarton Hospitals.

ORCID Number: 0000-0001-8902-2684

2. Shivesh Maharaj: MBBCh MMed. FCORL(SA), Academic Head, Dept of Otorhinolaryngology, Wits University. ORCID Number: 0000-0002-2118-2004

Corresponding author: Nadir Kana

Suite A, Netcare Milpark Hospital, 9 Guild Road, Parktown, Johannesburg, South Africa 2193.

Email: nadirkana@gmail.com

Author contributions:

1. Nadir Kana: Responsible for data collection, analysis and literature review $-60 \%$

2. Shivesh Maharaj: Responsible for editing - $40 \%$

This article is published in partial fulfillment of the requirements for the Degree of Master of Medicine by Dr N Kana.

\section{INTRODUCTION}

Sialendoscopy is a relatively new technique and before its advent, distal salivary gland obstructions were removed via an intraoral excision. ${ }^{1}$

The technique has evolved over the years and is now used across the world. The technique of sialendoscopy entails using semi-rigid endoscopes to cannulate and view the interior of the salivary ducts.

These endoscopes can be used as diagnostic as well as interventional tools as they have a hollow working channel that allows the passage of stone baskets, drills and fiber-optic lasers to fragment and remove calculi. Salivary duct obstruction is however not confined to salivary calculi alone, for obstructions may be caused by polyps, mucous plugs and strictures as well. ${ }^{2}$

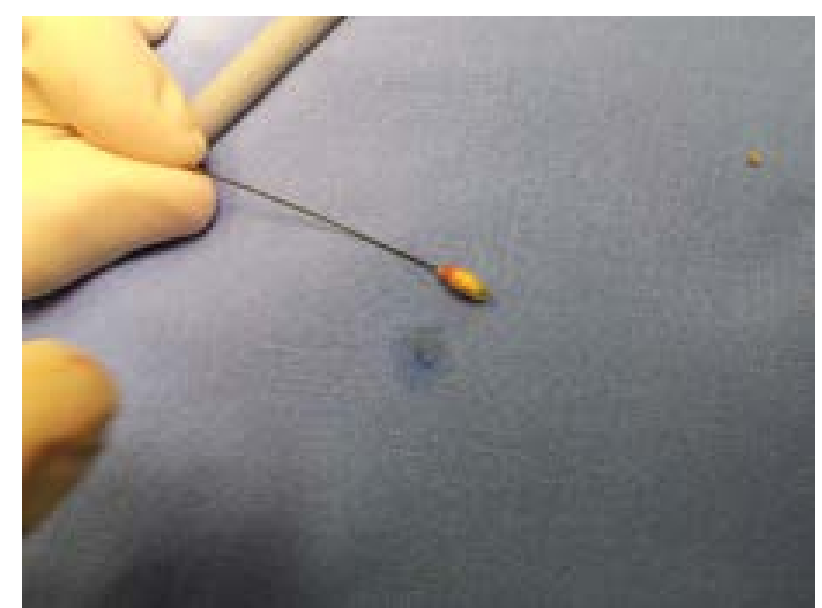

Figure 1. A stone basket with ensnared calculus.

Long term results of sialendoscopy are to be judged on:

1. Its ability to avoid gland resection with its concomitant complications.

2. Whether its results are long lasting.

3. Whether it has fewer and less severe complications than sialadenectomy. ${ }^{3,4}$

\section{LITERATURE REVIEW}

Sialendoscopy is associated with complications. However, these are minor complications in comparison with those encountered with sialadenectomy, which may be severe. Facial nerve injury is the most serious followed by Frey's Syndrome, lingual nerve injury and hypoglossal nerve injury. 
Facial and neck scarring are significant complications of the procedure. ${ }^{2}$

As with any new procedure it seems that there is a definite learning curve. According to Steck et al. failure to cannulate ducts and failure to remove stones appear to be the most common problems encountered in the first cases performed by surgeons. The complication rates are higher in the first 50 cases than seen in subsequent cases. ${ }^{5}$

According to Bowen et al. sialendoscopy is a safe and effective alternative to open surgery with low rates of major complications. Experience of options to overcome the tedious steps, like dilation of the ductal meatus and well planned case selection, are key to success.

The ultimate aim of sialendoscopy would be to diagnose and treat salivary duct obstruction quickly and efficiently without the need for general anaesthesia. This efficiency can only be attained with experience. ${ }^{6}$

Luers et al. concluded that it required 30 cases to improve skills to a level adequate to achieve satisfactory operation times, but true proficiency ensued after the first 50 cases. In this study the average operative times were 39 minutes and there was a significant improvement after the $10^{\text {th }}$ case and then again after the $30^{\text {th }}$ case. $^{7}$

Traditionally the old gold standard in diagnosing salivary duct obstruction was the sialogram. It has been superseded by ultrasound, CT (computerized tomography) scan and MRI (magnetic resonance imaging) scanning. The advantage of sialography is that it can show the salivary ductal system beyond a calculus.

None of these investigations offer the simultaneous diagnostic and therapeutic intervention that is possible with sialendoscopy.

\section{METHODS}

Study design

This is a record review of the files of patients who underwent sialendoscopies in a private practice setting in South Africa. Adult patients of all age groups were included. The duration of the study was from 2008 to 2018.

The variables extracted from the clinical records were as follows:

1. Age

2. Sex

3. Unilateral vs Bilateral Disease:

4. Type of gland

5. Radiological findings vs Sialendoscopy findings

6. Complications

7. Duration of follow up

8. Further treatment required

9. Successful sialendoscopy was defined as:

a). Identification of a cause of obstruction, from a diagnostic point of view.

b). A symptom-free patient on follow up, from a therapeutic point of view

\section{RESULTS}

\section{Demographics}

There were 39 patients in the original sample. 24 were excluded due to lack of consent. Of the remaining 15 cases, six were male and nine were female. Eight were parotid duct obstructions and seven were submandibular duct obstructions. There were two cases with bilateral sialadenitis, thus for 15 patients, 17 glands underwent sialendoscopy.

\section{Investigations performed}

Sialograms were performed in seven cases, all of which showed obstructions. Ultrasound was undertaken in four cases, three unilateral and one bilateral, showing obstructions in three out of the five glands.

One case was a failed sialendoscopic extraction of a calculus at another centre, that nonetheless had proven the existence of a calculus. The remaining three cases underwent CT scans preoperatively. Two were unilateral cases and one was bilateral. Of these four glands, CT scanning showed pathology in two.

Sialendoscopy found pathology in all the cases investigated with sialograms. In one case ultrasound showed a false positive as sialendoscopy did not find a calculus as had been indicated by the ultrasound.

Sialendoscopy correlated well with a negative CT scan of bilateral enlarged parotid glands in one patient. CT scan demonstrated false positive results in two glands where no calculi were found on sialendoscopy.

\section{Outcomes/complications}

From the 15 cases four can be considered failures. Two were abandoned due to excessive bleeding and one due to the extraction basket breaking. One of the abandoned cases complicated with abscess formation and had to be converted to a submandibulectomy.

One patient with bilateral recurrent parotitis had three calculi successfully removed on one side but only debris was found on the other side. The procedure had to be repeated a second time on this side due to symptom recurrence.

The second attempt again did not show calculi and only debris was found. However, after the second sialendoscopy the patient has been symptom free.

\section{Statistical tests performed}

To determine whether there was an association between variables, Chi-square tests of independence were performed. Only 15 data points were available due to the small sample size.

Both the critical values and the $p$-values were calculated. Tests were carried out at a $5 \%$ level of significance. In some cases, a phi value was calculated to test correlation between variables. 


\section{Hypotheses tested}

i). Whether successful sialendoscopy is associated with gender:

The test was done using a chi-square test of independence. and a p-value of 0.633533 was calculated.

This is larger than 0.05 and therefore fails to reject the null hypothesis. There is no significant proof that gender plays a role in a successful sialendoscopy.

ii). Whether successful sialendoscopy is associated with age:

The test was done using a chi-square test of independence and $p$-value of 0.439039 was calculated.

This is larger than 0.05 and therefore fails to reject the null hypothesis. There is no significant proof that age plays a role in a successful sialendoscopy.

iii). Whether successful sialendoscopy is associated with gland type:

Test was done using a chi-square test of independence and a p-value of 0.1855 was calculated.

This is larger than 0.05 and therefore fails to reject the null hypothesis. There is no significant proof that gland type plays a role in a successful sialendoscopy.

iv). Whether successful sialendoscopy is associated with unilateral/bilateral obstruction:

Test was done using a chi-square test of independence and a p-value of 0.359626 was calculated.

This is larger than 0.05 and therefore fails to reject the null hypothesis. There is no significant proof that whether the obstruction is unilateral or bilateral plays a role in a successful sialendoscopy.

v). Whether sialendoscopy is more successful with certain types of glands?

The two data points that had no obstructions shown in the sialendoscopy were removed, leaving 13 data points.

The data pertinent to the Parotid and Submandibular glands were subjected to a chi-square test of independence to determine whether there was a predilection for either of these glands suffering a calculus or a stricture.

A p-value of 0.260914 was calculated. This is larger than 0.05 and the null hypothesis may not be rejected. There is no significant proof that there is an association between gland type and different types of obstructions.

\section{vi). Whether successful sialendoscopy is associated} with gender:

Test was done using a chi-square test of independence and a P-value of 0.792212 was calculated.

This is larger than 0.05 and the null hypothesis may therefore not be rejected. There is no significant proof that there is an association between gender and obstructive disease in the salivary glands. Again, the data does not contain many patients who do not present with obstructive disease. A much larger sample of the general population would need to be carried out to determine the significance of this test accurately.

vii) Sialendoscopy vs. radiology

Radiology accurately diagnosed the problem only $73.3 \%$ of the time Sialendoscopy was accurate $100 \%$ of the time in cases where there were no complications. However, there were indeed two failures which means that its accuracy was $86.7 \%$.

\section{Diagnostic sialendoscopy vs. radiology}

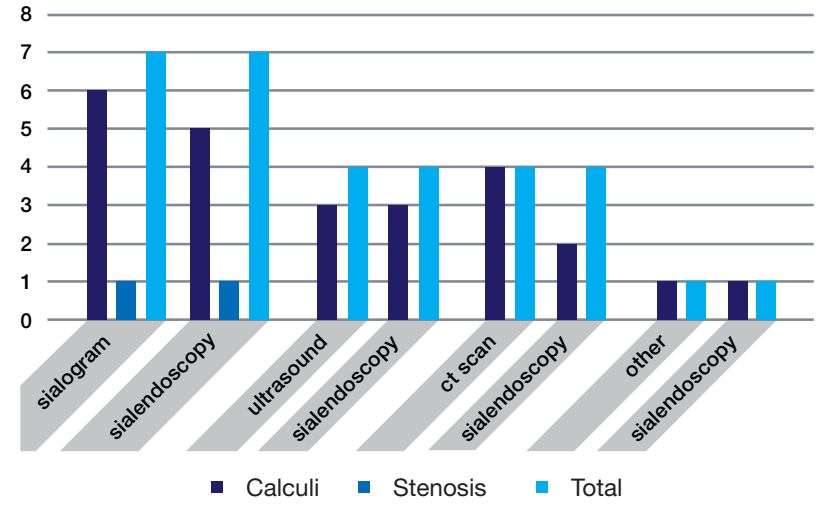

Figure 2. Diagnostic sialendoscopy vs. radiology.

Sialendoscopy procedure success vs. failure

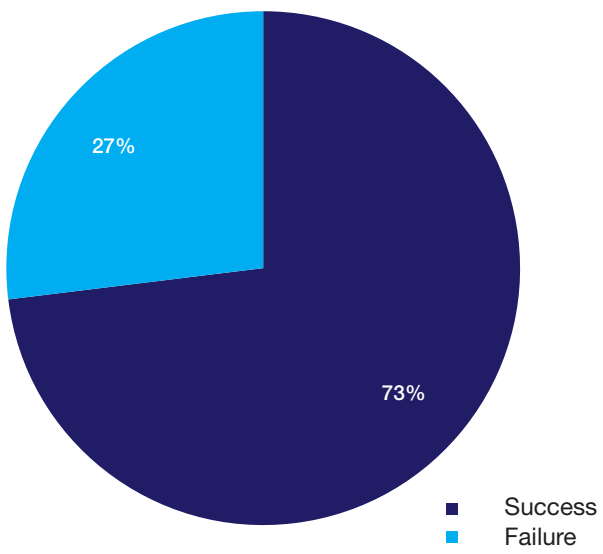

Figure 3. Success rate of sialendoscopy as a management tool. In this dataset a success rate of $73.3 \%$ was recorded (only four 'failures' in the dataset of 15)

\section{DISCUSSION}

Sialendoscopy is a relatively recent tool in the management of obstructive diseases of the major salivary ducts and it is gaining popularity. Since histopathological studies have shown that salivary glands which have been excised due to sialolithiasis have normal glandular architecture, ${ }^{8}$ glandular preservation of the gland should be the primary goal of treatment. ${ }^{9}$ 
Papadopolou et al. perform sialendoscopy under general anaesthesia in children under 8 years of age and under local anaesthesia for children over the age of 8. Their study was conducted retrospectively on sialendoscopies performed on children for juvenile recurrent parotitis. ${ }^{10}$

A study by Gallo et al., in which 1152 sialendoscopies were performed, showed a male to female preponderance of $52 \%$ vs $48 \%$. Sialoliths made up $53.1 \%$ of the pathology in this sample. The majority of cases were of the submandibular glands at $55.4 \%$ and parotid gland cases accounted for the remaining $44.6 \%$ of cases. ${ }^{11}$

Deenadayal et al. found in their study of 133 cases that obstruction was found bilaterally in 26 cases, 10 cases were normal, and pathology was found in a total 149 glands. 78 patients were male, and 55 patients were female. ${ }^{16}$ were paediatric cases. The age range of the study population was from 3 to 76 years. The cases were not all evaluated by ultrasound, but 54 cases were, and pathology was detected in 27 patients. Twenty two of these had calculi, four appeared to have Sjogren's disease and one had sialectasia. ${ }^{12}$

Salivary duct strictures are the second most common cause of ductal obstruction. They represent $25 \%$ of obstructive cases. It is difficult to demonstrate a stricture with MRI or CT scanning. Sialography can demonstrate strictures. Dilation of a salivary duct after applying a sialogogue can be demonstrated on ultrasound, indirectly showing a stricture. ${ }^{13}$

Strictures are less common in Wharton's duct than in Stensen's duct. The more distal strictures are amenable to open surgery as they are easily accessible orally. ${ }^{14}$

Koch et al. undertook in 2014 a study of 82 patients with parotid duct stenosis, treated with sialendoscopic dilatation. ${ }^{4}$ After an average follow-up period of 98.48 months, $50 \%$ percent of the patients reported having recurrent gland swelling but only $19.5 \%$ reported recurrent pain. Independent of the type of stenosis, a significant reduction in symptoms and improvement in the perceived quality of life after the treatment was observed.

Follow-up examinations were carried out in $20.73 \%$ of the patients and repeat sialendoscopy was performed in $12.1 \%$ of the patients. ${ }^{4}$ Recurrent stenoses were alleviated in every case. The glands were saved in every patient.

Long-term follow up after sialendoscopic dilatation of stenoses of Stensen's duct show that high success rates, good gland preservation rates and good patient perceived outcomes are attainable. ${ }^{4}$

Patient satisfaction appears good from the aforementioned data. What remains to be shown is whether normal salivary gland function continues after ductal obstruction is relieved. According to Marchal et al., the histopathologic grade of 48 submandibular glands resected due to sialolithiasis and examined by the same histopathologist did not correlate with the frequency and duration of symptoms. ${ }^{15}$
Therefore, multiple infections or prolonged duration of symptoms are not good predictors of the severity of functional loss of submandibular glands excised due to salivary calculi.

Despite the lack of evidence of a direct link between histologic findings and function, the widespread misconception is that submandibular glands with calculi must be excised as they are no longer functional. ${ }^{15}$

Some indications for sialadenectomy include:

1. Multiple failed stricture dilatations.

2. Massive or multiple intraparenchymal calculi with recurrent sialadenitis.

3. Complications during sialendoscopy procedures such as bleeding and stone basket entrapment.

4. Hilar or parenchymal calculus removal failure.

5. Persistent symptomatic sialadenitis in Sjogren's syndrome patients.

6. Patients previously treated with radioactive iodine with persistent symptomatic sialadenitis. ${ }^{2}$

\section{CONCLUSION}

Sialendoscopy offers good outcomes for both diagnosis and non-invasive treatment of the majority of cases of salivary ductal obstruction and is the gold standard for the management of this pathology.

\section{Acknowledgements}

Dr M Thandar for kindly providing patient data.

I would also like to thank Katey Dudley for her assistance with statistics.

\section{Ethics approval}

The study is unconditionally approved by the Human Research Ethics Committee of The University of the Witwatersrand. The Clearance Certificate number is M111130.

Informed consent was obtained from all 15 patients included in the study

\section{Conflict of interest}

The authors declare that they have no financial or personal relationships which may have inappropriately influenced them in writing this article.

\section{References}

1. Al-Abri R, Marchal F. New era of endoscopic approach for sialolithiasis: sialendoscopy, Sultan Qaboos University Medical Journal 2010; 10(3): 382-7.

2. Capaccio P, Torretta S, Pignataro L. The role of adenectomy for salivary gland obstructions in the era of sialendoscopy and lithotripsy. Otolaryngologic Clinics of North America 2009; 42(6): 1161-71.

3. Koch $\mathrm{M}$, Iro $\mathrm{H}$, Klintworth $\mathrm{N}$ et al. Results of minimally invasive gland-preserving treatment in different types of parotid duct stenosis. Archives of Otolaryngology-Head and Neck Surgery 2012; 138(9): 804-10. Available from: ttp://archotol.jamanetwork.com/article.aspx?doi=10.1001/ archoto.2012.1618. 


\begin{tabular}{|c|c|c|c|c|c|}
\hline Patient number & Age (Years) & Sex & Unilateral or bilateral & Submandibular & Parotid \\
\hline MU1 & 39 & Male & Left & $x$ & \\
\hline MU2 & 47 & Male & Left & $x$ & \\
\hline MU3 & 35 & Female & Right & & $x$ \\
\hline MU4 & 62 & Female & Left & & $x$ \\
\hline MU5 & 44 & Female & Right & & $x$ \\
\hline MU6 & 47 & Female & Right & $x$ & \\
\hline MU7 & 63 & Female & Right & $x$ & \\
\hline MU8 & 35 & Male & Right & $x$ & \\
\hline MU9 & 39 & Female & Bilateral & & $x$ \\
\hline MU11 & 40 & Male & Left & $x$ & \\
\hline MU12 & 17 & Female & Left & & $x$ \\
\hline DU1 & 66 & Male & Left & & $x$ \\
\hline DU2 & 48 & Male & Right & & $x$ \\
\hline DU3 & 44 & Female & Right & $x$ & \\
\hline DU4 & 37 & Female & Bilateral & & $x$ \\
\hline
\end{tabular}

\begin{tabular}{|c|c|c|c|c|c|c|}
\hline $\begin{array}{l}\text { Patient } \\
\text { number }\end{array}$ & Radiology findings & Sialendoscopy findings & Other treatments & Complications & Follow-up & $\begin{array}{l}\text { Further treatment } \\
\text { required }\end{array}$ \\
\hline MU1 & $\begin{array}{l}\text { Sialogram: One calcu- } \\
\text { lus left wharton's duct }\end{array}$ & $\begin{array}{l}\text { One calculus extracted } \\
\text { from left wharton's duct }\end{array}$ & None & None & 3 Years & None \\
\hline MU2 & $\begin{array}{l}\text { Ultrasound: One left } \\
\text { wharton's duct calculus }\end{array}$ & $\begin{array}{l}\text { Procedure abandoned } \\
\text { due to excessive } \\
\text { bleeding }\end{array}$ & $\begin{array}{l}\text { 1. Left submandibulectomy } \\
\text { performed } \\
\text { 2. Incision and drainage of } \\
\text { wound abscess }\end{array}$ & $\begin{array}{l}\text { Abscess } \\
\text { formation }\end{array}$ & 1 Month & None \\
\hline MU3 & $\begin{array}{l}\text { Sialogram: One right } \\
\text { stensen's duct calculus }\end{array}$ & $\begin{array}{l}\text { One calculus broken } \\
\text { down with drill and } \\
\text { extracted, right } \\
\text { stensens duct }\end{array}$ & None & None & $\begin{array}{l}\text { Lost to } \\
\text { follow up }\end{array}$ & None \\
\hline MU4 & $\begin{array}{l}\text { Sialogram: One left } \\
\text { stensen's duct stricture }\end{array}$ & $\begin{array}{l}\text { Left stensen's duct } \\
\text { stricture dilated using } \\
\text { scope and basket }\end{array}$ & None & None & 5 Years & None \\
\hline MU5 & $\begin{array}{l}\text { Ultrasound: Two right } \\
\text { stensen's duct calculi }\end{array}$ & $\begin{array}{l}\text { Two calculi in right } \\
\text { stensen's duct drilled } \\
\text { and extracted }\end{array}$ & None & None & $\begin{array}{l}\text { Lost to } \\
\text { follow up }\end{array}$ & None \\
\hline MU6 & $\begin{array}{l}\text { Sialogram: One right } \\
\text { wharton's duct calculus }\end{array}$ & $\begin{array}{l}\text { Procedure abandoned } \\
\text { due to bleeding }\end{array}$ & None & None & $\begin{array}{l}\text { Lost to } \\
\text { follow up }\end{array}$ & None \\
\hline MU7 & $\begin{array}{l}\text { Sialogram: One calcu- } \\
\text { lus in right wharton's } \\
\text { duct }\end{array}$ & $\begin{array}{l}\text { Failed extraction: basket } \\
\text { broken }\end{array}$ & Right submandibulectomy & None & $\begin{array}{l}\text { Lost to } \\
\text { follow up }\end{array}$ & None \\
\hline MU8 & $\begin{array}{l}\text { Failed sialendoscopy } \\
\text { at another centre: right } \\
\text { wharton's duct calculus } \\
\text { identified }\end{array}$ & $\begin{array}{l}\text { One calculus re-extracted } \\
\text { from right wharton's duct }\end{array}$ & None & None & 1 Week & None \\
\hline MU9 & $\begin{array}{l}\text { Ultrasound: prominent } \\
\text { parotid glands }\end{array}$ & $\begin{array}{l}\text { No calculi found. } \\
\text { No strictures found. }\end{array}$ & None & None & 1 Week & None \\
\hline MU11 & $\begin{array}{l}\text { CT: One left wharton's } \\
\text { duct calculus }\end{array}$ & $\begin{array}{l}\text { Left wharton's duct } \\
\text { calculus lasered and } \\
\text { extracted }\end{array}$ & None & None & 3 Months & None \\
\hline MU12 & $\begin{array}{l}\text { Sialogram: no calculus } \\
\text { identified left check }\end{array}$ & $\begin{array}{l}\text { Calculus found in left } \\
\text { proximal check duct }\end{array}$ & None & None & 3 Months & None \\
\hline DU1 & $\begin{array}{l}\text { Sialogram: Left parotid } \\
\text { calculi }\end{array}$ & $\begin{array}{l}\text { Two calculi in left parotid } \\
\text { duct }\end{array}$ & None & None & $\begin{array}{l}10 \\
\text { Months }\end{array}$ & $\begin{array}{l}\text { Left parotid recurrent } \\
\text { calculus abscess. } \\
\text { External incision and } \\
\text { extraction performed }\end{array}$ \\
\hline DU2 & $\begin{array}{l}\text { CT: two calculi suspec- } \\
\text { ted in right parotid duct }\end{array}$ & No calculi found & None & None & 1 Week & None \\
\hline DU3 & $\begin{array}{l}\text { Ultrasound: One right } \\
\text { wharton's duct stone }\end{array}$ & One calculus extracted & None & None & 1 Week & None \\
\hline DU4 & $\begin{array}{l}\text { CT: Bilateral stensen's } \\
\text { duct calculi }\end{array}$ & $\begin{array}{l}\text { Left parotid: Three calculi } \\
\text { extracted } \\
\text { Right parotid: no calculi } \\
\text { found, debris only }\end{array}$ & None & $\begin{array}{l}\text { Symptoms } \\
\text { continued } \\
\text { right side }\end{array}$ & 1 Week & $\begin{array}{l}\text { Right sialendoscopy } \\
\text { repeated: debris } \\
\text { found. No calculi } \\
\text { identified }\end{array}$ \\
\hline
\end{tabular}


4. Koch M, Künzel J, Iro $\mathrm{H}$ et al. Long-term results and subjective outcome after gland-preserving treatment in parotid duct stenosis. The Laryngoscope 2014; 124(8): 1813-8.

5. Steck JH, Stabenow E, Volpi EM. The learning progression of diagnostic sialendoscopy. Brazilian Journal of Otorhinolaryngology 2016; 82(2): 170-6.

6. Bowen MA, Tauzin M, Kluka EA. Diagnostic and interventional sialendoscopy: a preliminary experience. The Laryngoscope 2011; 121(2): 299-303.

7. Luers JC, Damm M, Klussmann JP. The learning curve of sialendoscopy with modular sialendoscopes: a single surgeon's experience. Archives of Otolaryngology-Head \& Neck Surgery 2010; 136(8): 762-5.

8. Papadaki ME, McCain JP, Kim K, Katz RL, Kaban LB, Troulis MJ. Interventionalsia-loendoscopy: early clinical results. J Oral Maxillofac Surg. 2008; 66(5): 954-62.

9. Marchal F, Dulguerov P, Becker M, Barki G, Disant F, Lehmann W. Specificity of parotid sialendoscopy. Laryngoscope 2001; 111(2): 264-71.

10. Papadopoulou-Alataki E, Chatziavramidis A, Vampertzi O. Evaluation and management of juvenile recurrent parotitis in children from northern Greece. Hippokratia 2015; 19(4): 356. Available from: http://www.ncbi.nlm.nih.gov/pubmed/27688702.
11. Gallo A, Capaccio P, Benazzo M et al. Outcomes of interventional sialendoscopy for obstructive salivary gland disorders: an Italian multicentre study. Acta Otorhinolaryngologica Italica 2016; 36(6): 479. Available from: http://www.ncbi.nlm.nih.gov/ pubmed/28177330.

12. Deenadayal DS, Bommakanti V. Sialendoscopy: a review of 133 cases. International Journal of Otolaryngology and Head \& Neck Surgery 2016; 5(01): 28.

13. Erkul E, Gillespie MB. Sialendoscopy for non-stone disorders: The current evidence. Laryngoscope Investigative Otolaryngology 2016; 1(5): 140-5.

14. Koch M, Iro H, Künzel J et al. Diagnosis and gland-preserving minimally invasive therapy for Wharton's duct stenoses. The Laryngoscope 2012; 122(3): 552-8.

15. Marchal F, Becker M, Kurt AM et al. Histopathology of submandibular glands removed for sialolithiasis. Annals of Otology, Rhinology \& Laryngology 2001; 110(5): 464-9.

\section{Do the CPD questionnaire on page 515}

The Continuous Professional Development (CPD) section provides for twenty general questions and five ethics questions. The section provides members with a valuable source of CPD points whilst also achieving the objective of CPD, to assure continuing education. The importance of continuing professional development should not be underestimated, it is a career-long obligation for practicing professionals.

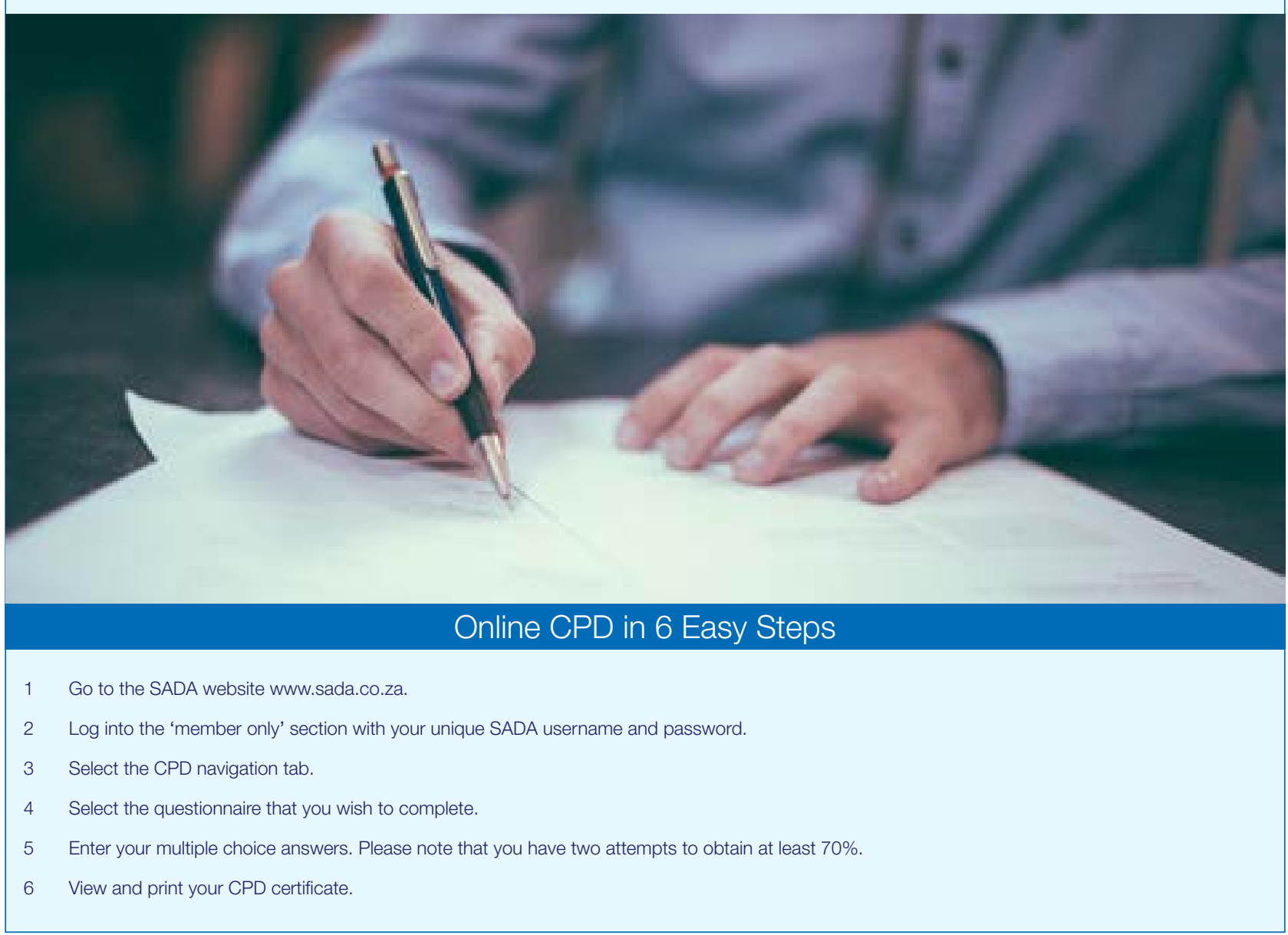

